Article

\title{
Homogeneous and Heterogeneous Catalysis Impact on Pyrolyzed Cellulose to Produce Bio-Oil
}

\author{
Siyi Li $@$, Shuo Cheng and Jeffrey S. Cross * \\ Energy Science and Engineering, Department of Transdisciplinary Science and Engineering, School of \\ Environment and Society, Tokyo Institute of Technology, 2-12-1 S6-15, Ookayama, Meguro, Tokyo 152-8552, \\ Japan; li.s.ai@m.titech.ac.jp (S.L.); cheng.s.ab@m.titech.ac.jp (S.C.) \\ * Correspondence: cross.j.aa@m.titech.ac.jp; Tel.: +81-3-5734-3723
}

Received: 27 January 2020; Accepted: 31 January 2020; Published: 3 February 2020

\begin{abstract}
Effectively utilizing catalytic pyrolysis to upgrade bio-oil products prepared from biomass has many potential benefits for the environment. In this paper, cellulose (a major component of plants and a biomass model compound) is pyrolyzed and catalyzed with different catalysts: $\mathrm{Ni}_{2} \mathrm{Fe}_{3}, \mathrm{ZSM}-5$, and $\mathrm{Ni}_{2} \mathrm{Fe}_{3} / \mathrm{ZSM}-5$. Two different pyrolysis processes are investigated to compare homogeneous and heterogeneous catalysis influence on the products. The results indicate that the $\mathrm{Ni}_{2} \mathrm{Fe}_{3}$ cluster catalyst shows the best activity as a homogeneous catalysis. It can also be recycled repeatedly, increases the yield of bio-oil, and improves the quality of the bio-oil by decreasing the sugar concentration. Furthermore, it also catalyzes the formation of a small amount of hydrocarbon compounds. In the case of $\mathrm{Ni}_{2} \mathrm{Fe}_{3} / \mathrm{ZSM}-5$ catalyst, it shows a lower yield of bio-oil but also decreases the sugar concentration significantly. $\mathrm{Ni}_{2} \mathrm{Fe}_{3}$, not only can it be used as homogeneous catalysis mixed with cellulose but also shows catalytic activity as a supported catalyst on ZSM-5, with higher catalytic activity than ZSM- 5 . These results indicate that the $\mathrm{Ni}_{2} \mathrm{Fe}_{3}$ catalyst has significant activity for potential use in industry to produce high quality bio-oil from biomass.
\end{abstract}

Keywords: catalysis; $\mathrm{Ni}_{2} \mathrm{Fe}_{3}$ cluster; pyrolysis; ZSM-5; bio-oil

\section{Introduction}

Current energy consumption worldwide mostly depends on fossil fuels, which will continue to be the dominant source of energy for the next several decades [1-3]. At the same time, carbon dioxide emissions from the use of fossil fuel increase every year [4], and the associated environmental problems have compelled researchers to look for innovative strategies to develop renewable energy sources and fuels.

Biofuels are an excellent candidate to replace fossil fuels and do not increase carbon emissions in the environment. Biofuels come in several forms, i.e., bio-oil, biodiesel, solid biofuels, and biogas. Bio-oil not only can help the economy by providing jobs but also could help reduce greenhouse gases and emit less pollution [5]. Japan Airlines Co., Ltd. plans to build a factory to transform biomass to bio-fuel for aircraft fuel to reduce $\mathrm{CO}_{2}$ emissions [6]. However, non-upgraded bio-oil is a complex mixture of oxygenated compounds, which reduces the energy content and density [7]. Many researchers have been working for decades to produce higher-quality fuels, using catalytic pyrolysis, hydrogenolysis, and other methods. Pyrolysis is a thermochemical process that decomposes organic matter under high temperatures in an inert atmosphere without oxygen. Compared to other thermochemical processing techniques, biomass pyrolysis is a well-established process that is a favorable renewable resource for energy recovery. During the catalytic pyrolysis process, the catalyst plays a significant role in the reactions for upgrading bio-fuel products. Most researchers prefer heterogeneous catalysis, the solid catalyst will not directly react with a reactant, i.e., it is only in contact with the pyrolyzed vapors 
during the reaction process. For example, Zhang's group studied the catalytic upgrading of corn stalk pyrolysis vapors with the HZSM- 5 zeolite catalyst. The oxygen content in organic pyrolysis vapors was decreased with a high-temperature hydrothermal treatment of HZSM-5 zeolite [8]; the fixed-bed reactor performance of Co/ZSM- 5 catalysts in the upgrading of lignocellulosic biomass pyrolysis vapors was also validated by Iliopoulou's group. All ZSM-5-based catalysts (metal promoted or not) had a significant effect on product yields and bio-oil composition, producing less bio-oil but of higher quality [9]. The property of Ni/ZSM-5 catalysts with varied nickel loadings was investigated by Yung's group, the catalyst interacted with pine pyrolysis vapors. Ni addition increased the yield of aromatic hydrocarbons and the conversion of oxygenates, while these effects are more pronounced with increasing Ni loading [10]. However, the heterogeneous catalysis reduced the yield but improved the quality of the oil products. Unfortunately, the catalyst lost its activity after 2-3 experimental runs, and was difficult to regenerate [11].

When compared to the heterogeneous catalysis, limited research has actually investigated homogeneous catalysis, in which the solid phase catalyst is directly mixed with the solid biomass feedstock for pyrolysis to produce bio-oil, the solid catalyst reacts with the solid reactant directly. Zhang's group studied the pyrolysis of corncobs with and without the H-ZSM- 5 catalyst and observed that the catalyst decreased the liquid and char yields [12]; Uzun's group studied different zeolite structures (ZSM-5, H-Y, and USY) for the catalytic pyrolysis of corn stalks. The highest oil yield was observed with ZSM-5 zeolite and the lowest with USY. The problem is these catalysts reduce the bio-oil yield and are hard to separate from the bio-char for recycling [13]. Especially, when these two different catalysis types are compared together [14,15].

The cluster catalyst has the potential to be an effective catalyst for pyrolysis due to a large specific heat capacity and thermal conductivity coefficient (a cluster is an ensemble of bound atoms or molecules that are intermediate in size between a molecule and a bulk solid). The absence of broad bulk phases leads to a high surface-to-volume ratio, which is advantageous in any catalyst application as this maximizes the reaction rate per unit amount of catalyst material. The metal cluster catalyst shows better properties than in the reported literature, such as $\mathrm{Fe}_{3}$ [16], $\mathrm{Ni} @ \mathrm{Ni}_{11} \mathrm{Fe}$ [17], etc. Our previous experimental results showed that the metal cluster catalyst can be recycled and showed excellent catalytic properties even after repeated catalytic experiments [18].

In this study, cellulose was chosen as the feedstock for pyrolysis, because it is a major component of biomass and is often used as a biomass model compound. It should be noted that cellulose does not melt to form a liquid phase at the pyrolysis temperature used in these experiments (see TG-DTA spectrum of cellulose with/without catalyst in Figure S1.) $\mathrm{Ni}_{2} \mathrm{Fe}_{3}$ cluster metal, ZSM-5, and $\mathrm{Ni}_{2} \mathrm{Fe}_{3} / Z \mathrm{ZSM}-5$ were selected as catalysts. Based on our previously published results, the $\mathrm{Ni}_{2} \mathrm{Fe}_{3}$ catalyst has shown great potential, like increasing the yield of bio-oil, improving the quality of oil and it can be recycled many times [18]. In contrast, ZSM-5 is a common catalyst used in the literature to upgrade bio-oil [12]. $\mathrm{Ni}_{2} \mathrm{Fe}_{3} / \mathrm{ZSM}-5$ was synthesized in order to compare it to ZSM-5 and to test the potential catalytic activity of $\mathrm{Ni}_{2} \mathrm{Fe}_{3}$. In order to investigate the potential of NiFe catalysts for industrial use, this study compared NiFe metallic particles, NiFe particles on supported ZSM- 5 catalysts and high surface area zeolite catalysts. The metallic particles have a low surface area, which is expected to help the heat transfer to the biomass whereas the zeolite catalyst is expected to catalyze the gas phase reactions. Hence, we distinguish these two types of two catalysis as homogeneous (NiFe) and heterogeneous catalysis (zeolite) to examine the overall bio-oil upgrade process in a fixed bed reactor at temperatures under $723.15 \mathrm{~K}$.

\section{Results and Discussion}

\subsection{XRD and SEM Analysis}

X-ray diffraction patterns of selected prepared catalysts powder samples and the symbols were of standard pattern peaks are shown in Figure 1. It indicates that the experimental XRD pattern agreed 
well with the peaks shown in the standard patterns. Meanwhile, there were not any spurious diffraction peaks found in the samples, indicating no other impurity component. The sol-gel and co-mixing methods were reliable for producing $\mathrm{Ni}_{2} \mathrm{Fe}_{3}$ and $\mathrm{Ni}_{2} \mathrm{Fe}_{3} / \mathrm{ZSM}-5$ supported catalysts. It should be noted that previous literature on the bimetallic catalysts ( $\mathrm{Ni}$ and $\mathrm{Fe}$ ) only exhibited a single peak indicating the formation of a Ni-Fe solid solution [19]. The intensity of XRD peaks of the sample in Figure 1 reflected that the formed particles were crystalline and broad diffraction peaks indicate very small size crystallites.

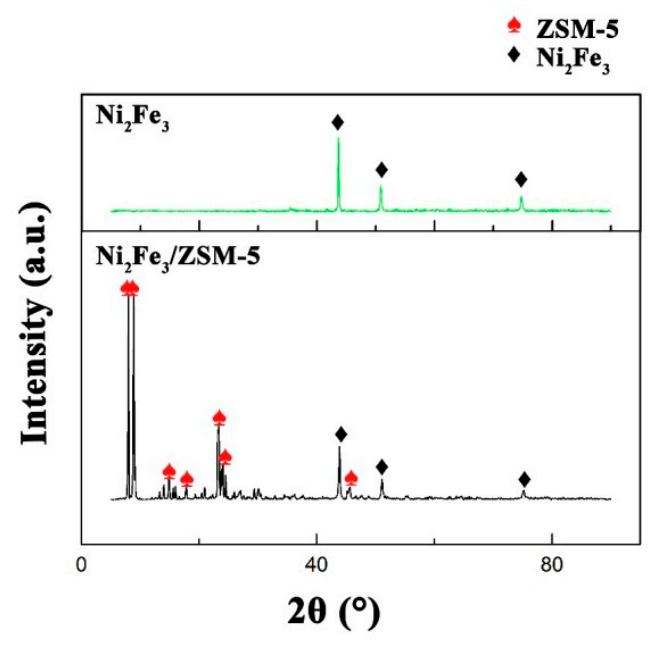

Figure 1. XRD analysis of prepared catalysts.

The SEM results in Figure 2a shows the image of the $\mathrm{Ni}_{2} \mathrm{Fe}_{3}$ catalyst particle with an uneven surface. A powdered structure usually exhibits better catalytic properties as indicated in the published literature [20]. Figure $2 \mathrm{~b}$ shows the image of $\mathrm{Ni}_{2} \mathrm{Fe}_{3} / \mathrm{ZSM}-5$ catalyst particle and energy-dispersive $X$-ray spectroscopy (EDS) results. The EDS spectrum indicates that $\mathrm{Ni}_{2} \mathrm{Fe}_{3}$ particles covered the ZSM- 5 surface well, and $\mathrm{Si} / \mathrm{Al}, \mathrm{O}, \mathrm{Ni}$, and Fe elements were detected. $\mathrm{Si} / \mathrm{Al}$ and $\mathrm{O}$ were the major components of ZSM-5, whereas $\mathrm{Ni}$ and Fe were from the $\mathrm{Ni}_{2} \mathrm{Fe}_{3}$ catalyst particles. The results indicated the co-mixing method was reliable for producing supported catalysts.

a)

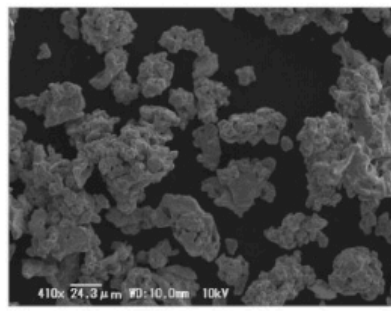

b)

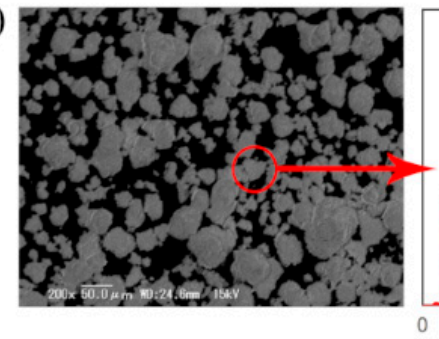

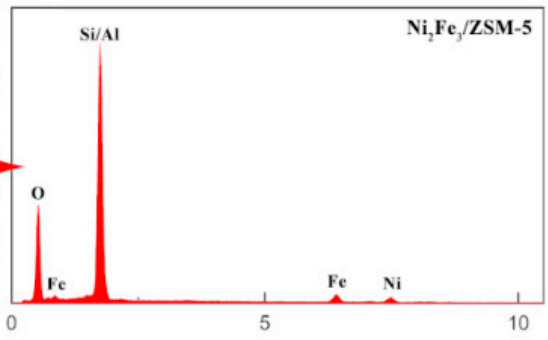

Figure 2. SEM images of (a) $\mathrm{Ni}_{2} \mathrm{Fe}_{3}$ catalyst particles and the (b) $\mathrm{Ni}_{2} \mathrm{Fe}_{3} / Z \mathrm{ZM}-5$ supported catalyst (including the energy-dispersive X-ray spectroscopy (EDS) spectrum).

\subsection{Pyrolysis Results}

\subsubsection{Comparison Among Different Catalysts for Homogeneous Catalysis}

Figure 3 shows the bio-oil, gas, and char/coke mass yields of the different catalysts. Three grams of the ZSM-5, $\mathrm{Ni}_{2} \mathrm{Fe}_{3} / \mathrm{ZSM}-5$, and $\mathrm{Ni}_{2} \mathrm{Fe}_{3}$ catalyst were separately mixed with $6 \mathrm{~g}$ of cellulose and placed in the reactor for pyrolysis experiments in order to compare different catalysts' influence on the homogeneous catalysis. The bio-oil yield from uncatalyzed cellulose pyrolysis was $39.2 \%$ and had a standard deviation near $1.0 \%$. The yields with all catalysts in the following order ZSM-5: $31.2 \% \pm 0.6 \%$ 
$<\mathrm{Ni}_{3} \mathrm{Fe}_{2} / \mathrm{ZSM}-5: 34.3 \% \pm 0.7 \%<$ No catalyst: $39.2 \% \pm 1.0 \%<\mathrm{Ni}_{2} \mathrm{Fe}_{3}: 46.7 \% \pm 0.5 \%$. It should be noted that the $\mathrm{Ni}_{2} \mathrm{Fe}_{3}$ metal catalyst usage improved the yield of bio-oil. However, other catalysts decrease the bio-oil yield typically as shown in previous studies that used $\mathrm{ZrO}_{2}$ and $\mathrm{TiO}_{2}$ and silica [21,22]. The reason for the bio-oil yield increase is attributed to differences in thermal conductivity coefficient and specific heat capacity. The specific heat capacity is the amount of heat energy required to raise the temperature of a substance per unit and the thermal conductivity coefficient is used to measure the property of transferring heat. The specific heat capacity is $0.38 \mathrm{kcal} / \mathrm{kg} \cdot \mathrm{K}$ for cellulose, $0.11 \mathrm{kcal} / \mathrm{kg} \cdot \mathrm{K}$ for $\mathrm{Ni}$, and $0.11 \mathrm{kcal} / \mathrm{kg} \cdot \mathrm{K}$ for Fe [23], respectively, which means nickel and iron both can transfer heat to the cellulose and increase the cellulose temperature quickly.

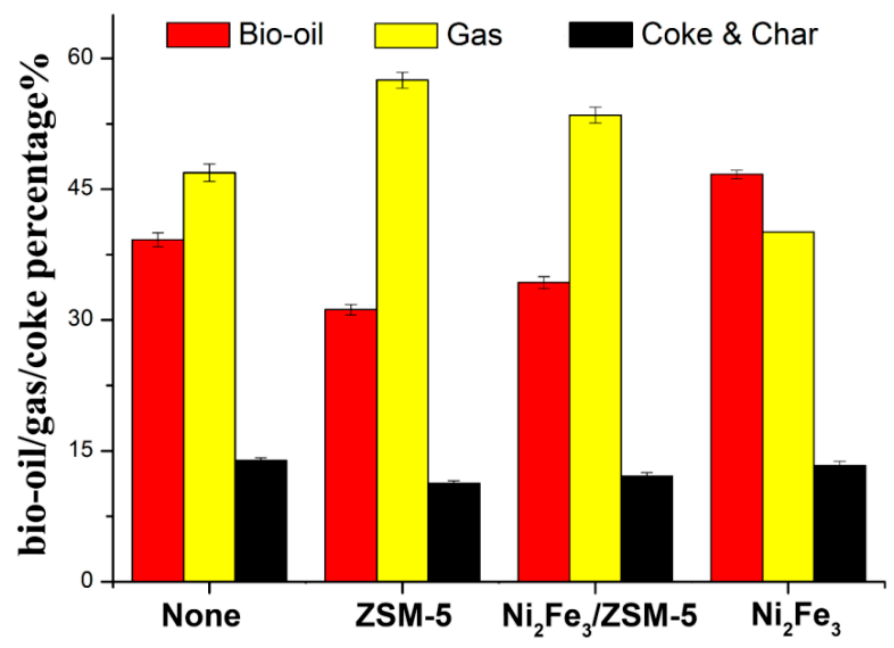

Figure 3. Bio-oil, gas, and char/coke yields from the pyrolysis of cellulose without/with the ZSM-5, $\mathrm{Ni}_{2} \mathrm{Fe}_{3} / \mathrm{ZSM}-5$, and $\mathrm{Ni}_{2} \mathrm{Fe}_{3}$ catalysts (homogeneous catalysis) and None: without catalysts.

In addition, the thermal conductivity coefficient is different, $0.23 \mathrm{~W} / \mathrm{m} \cdot \mathrm{K}$ for cellulose, $73.3 \mathrm{~W} / \mathrm{m} \cdot \mathrm{K}$ for $\mathrm{Ni}, 61.6 \mathrm{~W} / \mathrm{m} \cdot \mathrm{K}$ for $\mathrm{Fe}$, and $22.2 \mathrm{~W} / \mathrm{m} \cdot \mathrm{K}$ for $\mathrm{Ni}_{2} \mathrm{Fe}_{3}$ mixed with cellulose [18,24]. Ni and Fe are nearly 120 times higher than that of cellulose, which means for cellulose without a metallic catalyst being present, heat transfer from the reactor furnace to the cellulose is relatively poor. Some places or hot spots may develop in the cellulose when heated to a high temperature in a short time, which tends to produce gas. However, after adding a NiFe catalyst, the heat conductivity coefficient is enhanced 50 times, which can help transfer heat well in order to raise the bio-oil yield. It is also possible that some other reactions took place during the experiment impacting the yield, they will be investigated in future work.

Unlike the $\mathrm{Ni}_{2} \mathrm{Fe}_{3}$ metal catalyst, ZSM- 5 or $\mathrm{Ni}_{2} \mathrm{Fe}_{3} / \mathrm{ZSM}-5$ catalyst had lower bio-oil yields because the thermal conductivity coefficient of ZSM- 5 was only $1.1 \mathrm{~W} / \mathrm{m} \cdot \mathrm{K}$ and the specific heat capacity was $0.23 \mathrm{kcal} / \mathrm{kg} \cdot \mathrm{K}$. When compared to $\mathrm{Ni}_{2} \mathrm{Fe}_{3}$ catalysts, the lower specific heat capacity and thermal conductivity coefficient of ZSM-5 could not transfer heat very well from the furnace to the cellulose. In addition, the catalyst aggregated with cellulose, which was also observed by Zhang's group. They studied the pyrolysis of a corncob with and without the H-ZSM-5 catalyst and observed that the catalyst increased the yields of non-condensable gas, while it decreased the liquid and char yields [12]. The reason is that the sieve catalysts aggregate with the reactant, impeding part of the reactions for producing liquids and promoting reactions for gas. Moreover, $\mathrm{Ni}_{2} \mathrm{Fe}_{3} / \mathrm{ZSM}-5$ shows a slightly higher bio-oil yield than ZSM-5. The possible reason is the metal can increase the thermal conductivity coefficient of the reactant, which enhances the bio-oil yield. Further experiments will be conducted in the future to clarify possible mechanisms.

GC-MS equipment was used for analyzing all bio-oil samples. The identified peaks are presented in Table 1 and the specific compounds in the bio-oil are listed in Table S1. The main compounds were acids, furan, ketone, and sugars for all samples specifically, acetic acid, furfural, 2-propanone, 
1-hydroxy, and -beta.-D-Glucopyranose, 1,6-anhydro-, were also present respectively. On average, $3 \%$ of the peaks were unidentified. Pyrolysis of cellulose resulted in bio-oil containing hundreds of different compounds. For the purpose of making the comparison easier between different catalysts, the compounds were classified into different groups based on their functional group. These groups were classified as acids, alcohols, esters, furans, ketones, phenols, sugars, hydrocarbons (HC), and others. Table 1 indicates the major products of uncatalyzed cellulose products consisted of sugars $(48.8 \% \pm$ $1.7 \%)$, ketone $(17.0 \% \pm 2.6 \%)$, furans $(20.7 \% \pm 0.7 \%)$, and acids $(4.8 \% \pm 0.2 \%)$. In this study, phenolic compounds were also found in uncatalyzed cellulose pyrolysis products, the same as other researchers have reported [21]. The other main components of the bio-oils derive from non-catalytic and catalytic pyrolysis of cellulose were in good agreement with the literature results [25-27].

Table 1. Composition of cellulose pyrolyzed products with different catalysts (peak area\% of identified peaks, unidentifiable compounds are lumped together in the others category).

\begin{tabular}{cccccccccc}
\hline & Acid $\%$ & Alcohol $\%$ & Esters $\%$ & Furans\% & Ketones $\%$ & Phenols\% & Sugar\% & HC $\%$ & Others $\%$ \\
\hline None & $4.8 \pm 0.2$ & $2.3 \pm 0.1$ & $2.0 \pm 0.1$ & $20.7 \pm 0.7$ & $17.0 \pm 2.6$ & $1.6 \pm 0.4$ & $48.8 \pm 1.7$ & 0.0 & $2.1 \pm 1.2$ \\
ZSM-5 & $11.8 \pm 0.3$ & $0.7 \pm 0.1$ & $2.1 \pm 0.1$ & $13.3 \pm 0.4$ & $25.8 \pm 0.5$ & 0.0 & $43.3 \pm 1.2$ & 0.0 & $3.0 \pm 0.1$ \\
$\mathrm{Ni}_{2} \mathrm{Fe}_{3} / \mathrm{ZSM}-5$ & $12.6 \pm 0.3$ & $0.8 \pm 0.1$ & $2.4 \pm 0.1$ & $15.7 \pm 0.9$ & $28.3 \pm 1.2$ & 0.0 & $38.2 \pm 0.1$ & 0.0 & $2.0 \pm 0.1$ \\
$\mathrm{Ni}_{2} \mathrm{Fe}_{3}$ & $4.6 \pm 0.3$ & $2.3 \pm 0.1$ & $2.4 \pm 0.2$ & $25.9 \pm 0.7$ & $27.9 \pm 0.8$ & $2.2 \pm 0.2$ & $31.5 \pm 0.6$ & $0.5 \pm 0.4$ & $2.6 \pm 0.4$ \\
\hline
\end{tabular}

For the purpose of investigating how the different catalysts change the composition of the bio-oils with homogeneous catalysis, details are discussed below. Firstly, HC compounds were formed only in the presence of the $\mathrm{Ni}_{2} \mathrm{Fe}_{3}$ metal catalyst, which is an excellent component and indication that this compound is effective to improve the quality of bio-oil although the composition was only $1 \%$.

Secondly, reducing sugar concentration could improve the quality of bio-oil. Figure 4 shows how the different catalysts influence bio-oil sugar concentration and Table 1 shows the different sugar content in bio-oil with/without catalysts. Typically, all catalysts reduced the sugar content, and the $\mathrm{Ni}_{2} \mathrm{Fe}_{3}$ metal catalyst shows excellent activity to remove it. Not only because the catalyst has a unique cluster structure and reactive surface, but also because the composition of the Ni and Fe element, all show catalytic activity. The NiFe cluster catalyst is shown to be effective for removing sugar composition based on our previous study [28]. From Table 1, $\mathrm{Ni}_{2} \mathrm{Fe}_{3}, \mathrm{ZSM}-5$, and $\mathrm{Ni}_{2} \mathrm{Fe}_{3} / \mathrm{ZSM}-5$ decreased by $17.3 \%, 5.5 \%$, and $10.6 \%$ sugar concentration, respectively.

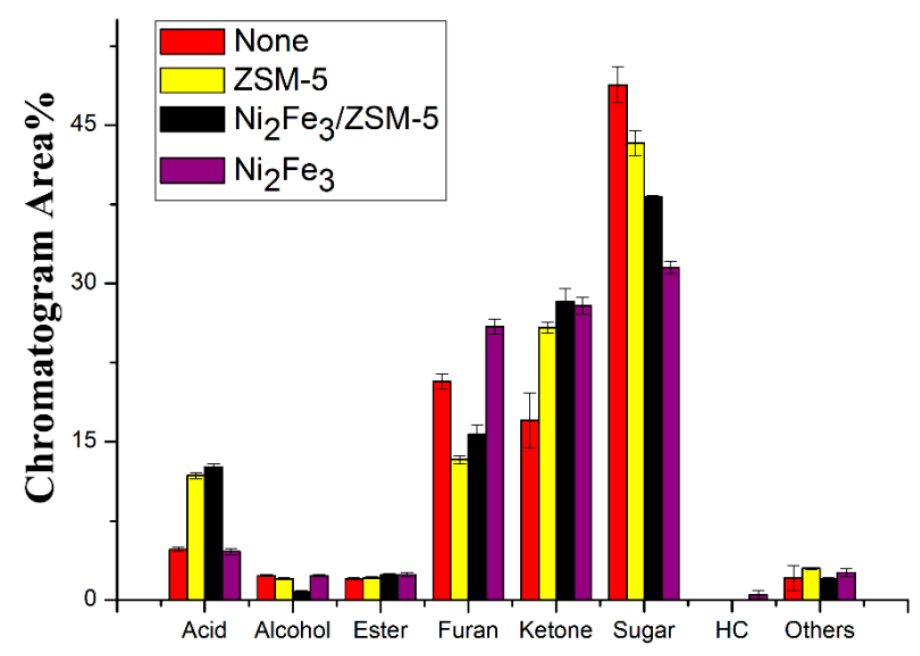

Figure 4. Chemical relative compositions of the organic phase of bio-oil without/with the ZSM-5, $\mathrm{Ni}_{2} \mathrm{Fe}_{3} / \mathrm{ZSM}-5$, and $\mathrm{Ni}_{2} \mathrm{Fe}_{3}$ catalysts (homogeneous catalysis) and None: without catalysts.

Thirdly, the three catalysts show different influences on the furan and ketone concentrations as shown in Figure 4. The $\mathrm{Ni}_{2} \mathrm{Fe}_{3}$ catalyst had a significant effect on increasing ketone and furan 
concentrations by improving the conversion efficiency of cellulose decomposition, especially by decreasing the sugar concentration. The first step is the cellulose decomposed into sugar, and then the sugar decomposed into furan and ketone. As shown in Table 1, the bio-oil component with $\mathrm{Ni}_{2} \mathrm{Fe}_{3}$ shows the sugar concentration decreasing while both furan and ketone concentrations increase. The GC-MS results show that the major reaction was levoglucose decomposed into 5-Hydroxymethylfurfural, Furfural, 5-methyl-, 1,2-Cyclopentanedione, 3-methyl-, 1,2-Cyclopenten-1-one, etc. The situation for ZSM-5 and $\mathrm{Ni}_{2} \mathrm{Fe}_{3} / \mathrm{ZSM}-5$ is a little different. They do not affect the furan concentration but only show selectivity to enhance ketone compositions. The levoglucose decomposes into 5-methyl-, 1,2-Cyclopentanedione, 3-methyl-, 1,2-Cyclopenten-1-one, etc. The reason why we focused on the ketone and furan composition is many different methods can further transform them into HC compounds to improve the quality of bio-oil with additional chemical reactions.

Finally, all catalysts did not significantly affect the other compound concentrations. Based on the above results, $\mathrm{Ni}_{2} \mathrm{Fe}_{3}$ was selected as the most active homogeneous catalysis when compared to other catalysts, because it increased the bio-oil yield, but also shows the highest activity to remove sugar content. Moreover, it is easy to separate the $\mathrm{Ni}_{2} \mathrm{Fe}_{3}$ catalyst from char by magnetic separation, and the "new" (unused) catalyst shows the same catalytic activity when compared to the used catalyst based on previously reported results [18].

\subsubsection{Comparison Between Different Catalysts for Heterogeneous Catalysis}

Figure 5 shows the bio-oil, gas, and coke mass yields of two different supported catalysts with and without metal clusters. For ZSM- 5 and $\mathrm{Ni}_{2} \mathrm{Fe}_{3} / Z \mathrm{ZSM}-5$, the catalyst had a large surface area, which will enhance reaction with vapors. The surface area of the ZSM-5 used in the present study was $310 \mathrm{~m}^{2} / \mathrm{g}$, and the surface area of $\mathrm{Ni}_{2} \mathrm{Fe}_{3} / \mathrm{ZSM}-5$ was lower $\left(278 \mathrm{~m}^{2} / \mathrm{g}\right) . \mathrm{Ni}_{2} \mathrm{Fe}_{3}$ was not as effective as a heterogeneous catalysis because of its low surface area $\left(2 \mathrm{~m}^{2} / \mathrm{g}\right)$. Three grams of ZSM-5 and $\mathrm{Ni}_{2} \mathrm{Fe}_{3} / \mathrm{ZSM}-5$ were put on a metal net for pyrolysis experiments to catalyze pyrolyzed vapor in order to compare different catalysts for heterogeneous catalysis. The bio-oil yield from uncatalyzed cellulose pyrolysis was $39.2 \%$ and had a standard deviation near $1.0 \%$. The yield was $33.8 \% \pm 0.5 \%$, for ZSM- 5 and $31.0 \% \pm 0.3 \%$ for $\mathrm{Ni}_{2} \mathrm{Fe}_{3} / \mathrm{ZSM}-5$, respectively. From the results, ZSM- 5 and $\mathrm{Ni}_{2} \mathrm{Fe}_{3} / \mathrm{ZSM}-5$ reduced the bio-oil yield by $5 \%$ and $8 \%$, respectively. The result was the same as the Iliopoulou group's result [29], where the liquid yield decreased after introducing the Ni modified ZSM-5. The reason is the added metal to the surface decreases the surface area of the original ZSM-5, allowing less vapor to enter the porous catalyst.

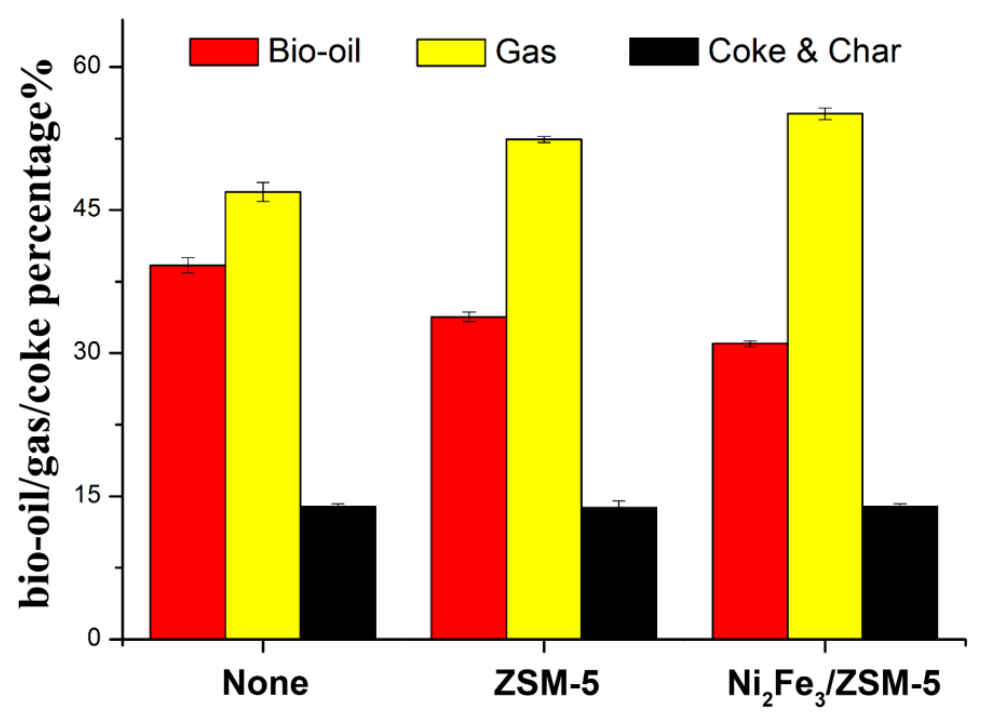

Figure 5. Bio-oil, gas, and char/coke yields from pyrolysis of cellulose without/with the ZSM-5 and $\mathrm{Ni}_{2} \mathrm{Fe}_{3} / \mathrm{ZSM}-5$ catalysts (heterogeneous catalysis) and None: without catalysts. 
GC-MS was used for analyzing all bio-oil samples in order to determine the composition of the bio-oils. The results of the identified peaks are presented below in Table 2 and the specific compounds are listed in Tables S1, S5 and S6. The main compounds of acids, furan, ketone, and sugars for all samples, specifically acetic acid, furfural, 2-propanone, 1-hydroxy, -beta.-D-Glucopyranose, and 1,6-anhydro- were also present respectively. These supported catalysts did not have a strong influence on the major products. The compounds were also classified into different groups based on their functional groups. In order to find how the different catalysts impacted the composition of the bio-oils by heterogeneous catalysis, some important activity will be discussed in detail below and data shown in Figure 6.

Table 2. Composition of cellulose pyrolyzed products with different catalysts (peak area \% of identified peaks, unidentifiable compounds are lumped together in others category).

\begin{tabular}{cccccccccc}
\hline & Acid $\%$ & Alcohol $\%$ & Esters\% & Furans $\%$ & Ketones $\%$ & Phenols\% & Sugar\% & HC\% & Others $\%$ \\
\hline None & $4.8 \pm 0.2$ & $2.3 \pm 0.1$ & $2.0 \pm 0.1$ & $20.7 \pm 0.7$ & $17.0 \pm 2.6$ & $1.6 \pm 0.4$ & $48.8 \pm 1.7$ & 0.0 & $2.1 \pm 1.2$ \\
ZSM-5 & $12.3 \pm 0.5$ & $1.3 \pm 0.1$ & $4.9 \pm 0.2$ & $20.7 \pm 1.6$ & $30.1 \pm 0.8$ & $2.8 \pm 0.3$ & $25.6 \pm 0.9$ & 0.0 & $2.3 \pm 0.1$ \\
$\mathrm{Ni}_{2} \mathrm{Fe}_{3} / \mathrm{ZSM}-5$ & $11.2 \pm 0.3$ & $2.0 \pm 0.1$ & $3.6 \pm 0.4$ & $20.3 \pm 1.3$ & $37.6 \pm 2.7$ & $1.7 \pm 0.3$ & $19.1 \pm 0.2$ & $0.4 \pm 0.1$ & $4.1 \pm 0.1$ \\
\hline
\end{tabular}

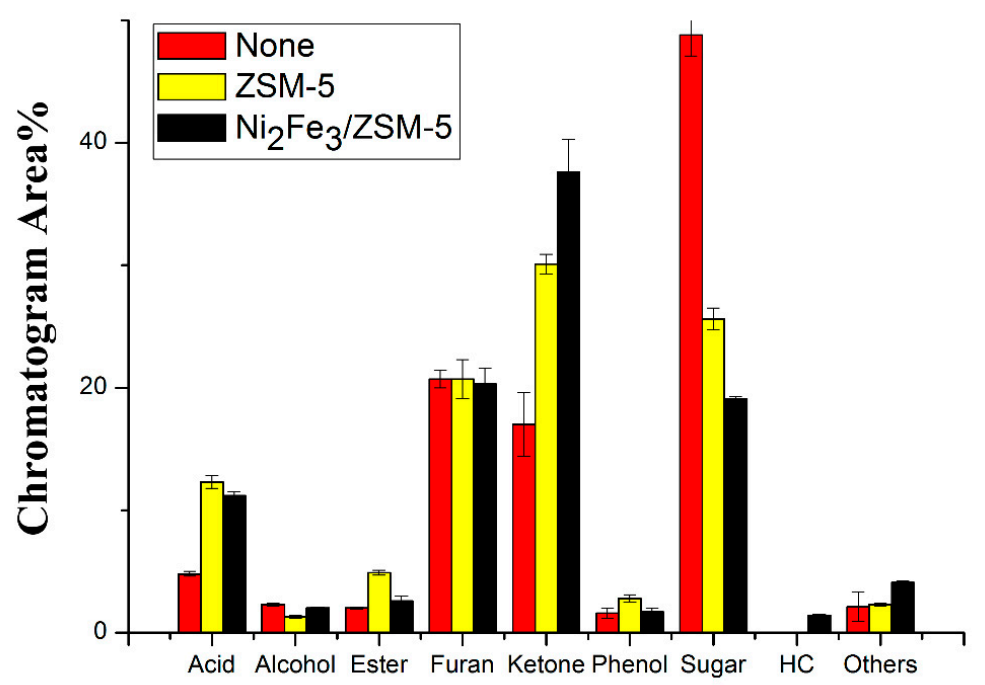

Figure 6. Chemical relative compositions of the organic phase of bio-oil without/with the ZSM-5 and $\mathrm{Ni}_{2} \mathrm{Fe}_{3} /$ ZSM-catalysts (heterogeneous catalysis) and None: no catalyst.

Typically, both catalysts reduced the sugar content when compared to bio-oils produced without catalysts. Table 2 shows that ZSM- 5 and $\mathrm{Ni}_{2} \mathrm{Fe}_{3} / Z \mathrm{ZSM}-5$ decreased by $23.2 \%$ and $29.7 \%$ sugar content, respectively. The reason is their large surface area can improve vapor reactive efficiency. While ZSM- 5 surface modified by $\mathrm{Ni}_{2} \mathrm{Fe}_{3}$ improves the catalyst activity by reducing the sugar concentration similar to Cheng's results [30]. They used the Ni and Fe element to modify the HZSM-5, and found that the modified catalyst decreased the bio-oil yield, but increased the quality of bio-oil by removing more oxygen (sugar).

ZSM-5 and $\mathrm{Ni}_{2} \mathrm{Fe}_{3} / \mathrm{ZSM}-5$ catalyst show the same reaction selectively, for sugar and ketone. As indicated in Table 2, sugar content decreased while ketone concentration increased the sugar decompose into different types of ketone, like 5-methyl-, 1,2-Cyclopentanedione,3-methyl-, 1,2-Cyclopenten-1-one, etc. As mentioned above, ketone is an important product for upgrading the quality of bio-oil.

In summary, using $\mathrm{Ni}_{2} \mathrm{Fe}_{3}$ to modify typical ZSM-5 support is a useful strategy to synthesis a new supported catalyst to upgrade bio-oil. It can help reduce sugar and increase the ketone concentration in bio-oil without changing other components. 
After comparing the different catalyst types, the results indicate that overall the catalysts do not have a strong impact on the major products of the bio-oil. The $\mathrm{Ni}_{2} \mathrm{Fe}_{3}$ catalyst shows the best property as a homogeneous catalysis, which could be recycled repeatedly but also increased the yield of bio-oil, and improved the quality of the bio-oil, especially when compared with the other catalysts that decreased the bio-oil yield, like ZSM-5, and other groups' works [21,22]. These results indicate the potential of the NiFe cluster catalysts to lower the oxygen content of bio-oil. $\mathrm{Ni}_{2} \mathrm{Fe}_{3} / \mathrm{ZSM}-5$ shows a lower yield of bio-oil but also lower sugar content. ZSM- 5 and $\mathrm{Ni}_{2} \mathrm{Fe}_{3} / \mathrm{ZSM}-5$ improved the quality of bio-oil but also had lower bio-oil yields. Further work is underway to clarify the corresponding mechanisms.

\section{Experimental Method}

\subsection{Catalyst Preparation}

The biomass feedstock was powdered cellulose $(38 \mu \mathrm{m})$ from Wako Pure Chemical Industries Ltd. (Osaka, Japan). The ZSM-5 catalyst was purchased from Tosoh Corporation (Tokyo, Japan).

The $\mathrm{Ni}_{2} \mathrm{Fe}_{3}$ catalyst was prepared by the sol-gel method [31,32]. The chemicals were citric acid, $\mathrm{Fe}\left(\mathrm{NO}_{3}\right)_{3} \cdot 9 \mathrm{H}_{2} \mathrm{O}$, ethylene glycol, and $\mathrm{Ni}\left(\mathrm{NO}_{3}\right)_{2} \cdot 6 \mathrm{H}_{2} \mathrm{O}$, purchased from Wako Pure Chemical Industries (Osaka, Japan). The mol ratio between metal ion ( $\mathrm{Ni}$ and $\mathrm{Fe}$ ) and citric acid was 1:1.2. The preparation of catalysts was performed at room temperatures: $5.8 \mathrm{~g} \mathrm{Fe}\left(\mathrm{NO}_{3}\right)_{3} \cdot 9 \mathrm{H}_{2} \mathrm{O}$ and $12.1 \mathrm{~g} \mathrm{Ni}\left(\mathrm{NO}_{3}\right)_{2} \cdot 6 \mathrm{H}_{2} \mathrm{O}$ was dissolved in $30 \mathrm{~mL}$ of distilled water and stirred for $5 \mathrm{~h}$. Then $5 \mathrm{~mL}$ of ethylene glycol and $11.1 \mathrm{~g}$ of citric acid were added in a beaker. Then the transparent solution was stirred for $15 \mathrm{~h}$ at which time the solution became uniform. The transparent sol was dried at $110{ }^{\circ} \mathrm{C}$ in an oven for $20 \mathrm{~h}$ and calcined at $700{ }^{\circ} \mathrm{C}$ to burn off hydrocarbons under $95 \% \mathrm{~N}_{2}$ and $5 \% \mathrm{H}_{2}$ mix gas. Finally, the catalyst was crushed into a powder in a mortar and pestle. After repeating this process many times, enough catalyst was obtained. The $5 \mathrm{wt} \% \mathrm{Ni}_{2} \mathrm{Fe}_{3} / \mathrm{ZSM}-5$ catalyst was prepared by the co-mixing method [33,34] using $\mathrm{Ni}_{2} \mathrm{Fe}_{3}$ and ZSM- 5 . The mass of $\mathrm{Ni}_{2} \mathrm{Fe}_{3}$ in the ZSM- 5 used for $5 \mathrm{wt} \%$ loading was $0.5 \mathrm{~g}$. After mixing, the sample was dried at $90{ }^{\circ} \mathrm{C}$ for $1 \mathrm{~h}$ and then calcined in $95 \% \mathrm{~N}_{2}$ and $5 \% \mathrm{H}_{2}$ mix gas at $700{ }^{\circ} \mathrm{C}$ for $5 \mathrm{~h}$.

\subsection{Catalyst Preparation}

In order to compare different properties between homogeneous and heterogeneous catalysis, special pyrolysis equipment was designed as shown in Figure 7. For homogeneous catalysis, cellulose $(6 \mathrm{~g})$ was loaded in a $310 \mathrm{~mm}$ length and $50 \mathrm{~mm}$ diameter quartz reactor with $3 \mathrm{~g}$ of catalyst. The inner diameter of the electric furnace was $50 \mathrm{~mm}$, and the length was $330 \mathrm{~mm}$. Then the entire system was purged with flowing nitrogen gas for $10 \mathrm{~min}$ in order to expel all air. Afterward, the reactor was heated to the set temperature $\left(450^{\circ} \mathrm{C}\right)$ with a heating rate of $45^{\circ} \mathrm{C} / \mathrm{min}$. Then the nitrogen gas carried the pyrolyzed vapors from the reactor to the condenser. The vapors were condensed using cold water by the condenser. For heterogeneous catalysis, cellulose $(6 \mathrm{~g})$ was loaded in a $50 \mathrm{~mm}$ diameter quartz reactor alone and $3 \mathrm{~g}$ of catalyst was loaded on the metal net near the bottom of the tube, then the process was the same as the above reaction. The reaction time was $10 \mathrm{~min}$ after reaching the target temperature for each experiment. The bio-oil was removed from the flask and collected after the furnace temperature dropped below $300^{\circ} \mathrm{C}$, then the samples were filtered by filter paper (pore size $30-50 \mu \mathrm{m}, 70 \mathrm{~mm}$ diameter) to remove any particles and also by a syringe filter $(0.45 \mu \mathrm{m})$ for the GC-MS analysis pretreatment, finally, all samples were analyzed by GC-MS. The amount of bio-oil and char and coke were weighed, and then the amount of gas was calculated by subtracting the amount of bio-oil and char and coke from the initial feed. 


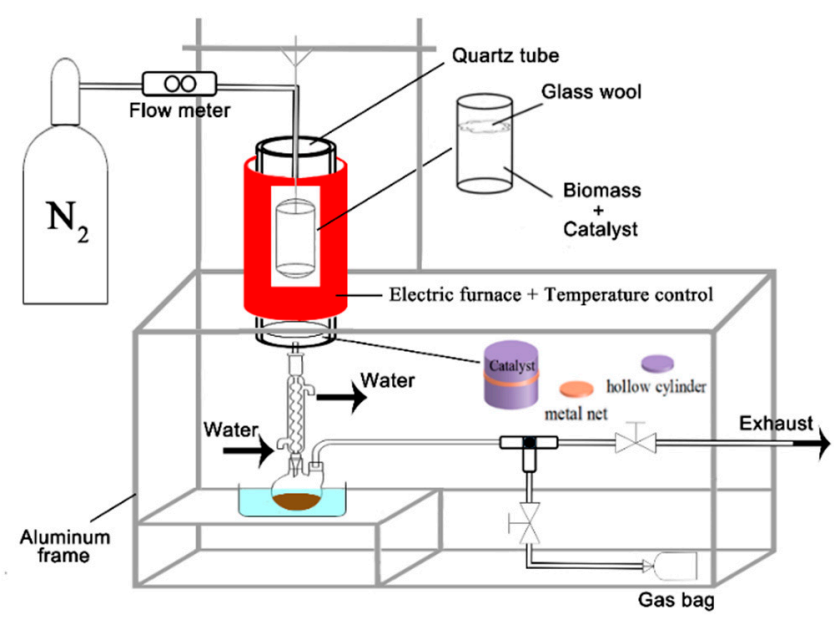

Figure 7. Experimental set-up for the pyrolysis experiment.

\subsection{XRD, BET, and the SEM-EDS Test}

The XRD analysis of catalysts was conducted by the X-ray Diffractometer (Mini Flex 600, Rigaku Ltd., Tokyo, Japan). For the X-ray tube operation, $46 \mathrm{kV}$ and $14 \mathrm{~mA}$ were used. The scan range (2 theta) of the XRD pattern was collected from 5 to $90^{\circ}$ using filtered $\mathrm{Cu}$ radiation.

Specific surface areas were measured using the Brunauer-Emmett-Teller method with $\mathrm{N}_{2}$ (BEL SORP mini; Bel Japan Inc., Tokyo, Japan).

Images of catalysts were obtained by a scanning electron microscope (VE-9800, Keyence Corporation, Tokyo, Japan) operated at $10 \mathrm{kV}$. The catalyst was firstly immersed in alcohol, and then the samples were loaded and dried on a copper grid (carbon-coated). The elemental composition of the $\mathrm{Ni}_{2} \mathrm{Fe}_{3} / \mathrm{ZSM}-5$ was also analyzed by the energy-dispersive $\mathrm{X}$-ray spectroscopy (EDS, Genesis XM2, EDAX Corporation, Tokyo, Japan).

\subsection{GC-MS Analysis Method}

In order to identify organic compounds and analyze the composition of the bio-oil samples, GC-MS equipment was used to analyze bio-oil samples. The analysis was performed on a GC-2010 Plus equipped with a GC-MS-QP2010 SE mass-detector made by Shimadzu Corporation (Tokyo, Japan). The column type was Stabilwax-DA $30 \mathrm{~m} \times 0.25 \mathrm{~mm}, 0.25 \mu \mathrm{m}$ diameter (Bellefonte, PA, USA). The analysis was run with a 10:1 split entry. The oven temperature was held at $40^{\circ} \mathrm{C}$ for $5 \mathrm{~min}$ and then ramped up to $50{ }^{\circ} \mathrm{C}$ and heated at $1{ }^{\circ} \mathrm{C} / \mathrm{min}$. Next, it was ramped up to $130^{\circ} \mathrm{C}$ at $2{ }^{\circ} \mathrm{C} / \mathrm{min}$. Finally, the temperature was ramped up to $260^{\circ} \mathrm{C}$ at $4{ }^{\circ} \mathrm{C} / \mathrm{min}$ and held for $10 \mathrm{~min}$. The compounds were identified by comparing the mass spectra to NIST 11 MS library of compounds using the GC-MS software. A similarity threshold of over 80 was used to identify the compounds. All GC-MS experiments were conducted in duplicates, and the standard deviations were calculated.

\section{Conclusions}

In this study, three different catalysts were chosen to test how the homogeneous and heterogeneous catalysis influences the pyrolyzed bio-oil compositions. For homogeneous catalysis, ZSM-5, $\mathrm{Ni}_{2} \mathrm{Fe}_{3} / Z \mathrm{ZM}-5$, and $\mathrm{Ni}_{2} \mathrm{Fe}_{3}$ catalysts were directly mixed with cellulose in the reactor for the pyrolysis experiments. The results show that the $\mathrm{Ni}_{2} \mathrm{Fe}_{3}$ metal catalyst used here improved the yield of bio-oil from $39.2 \%$ to $46.7 \%$, while others have previously reported a decreased yield. $\mathrm{The} \mathrm{Ni}_{2} \mathrm{Fe}_{3}$ catalyst reduced the sugar composition from $48.8 \%$ to $31.5 \%$ when compared to other catalysts. $\mathrm{Ni}_{2} \mathrm{Fe}_{3}$ was the best choice for homogeneous catalysis among those tested. Not only did it increase the bio-oil yield and show the highest activity to remove sugar, but it also can be recycled potential saving money if used as an industrial catalyst. 
For heterogeneous catalysis, ZSM- 5 and $\mathrm{Ni}_{2} \mathrm{Fe}_{3} / \mathrm{ZSM}-5$ were used to react with pyrolyzed vapors in the reactor. The results indicate that either catalyst reduced the yield of bio-oil, reducing the bio-oil yield by $5 \%$ and $8 \%$, respectively. Based on the GC-MS analysis, $\mathrm{Ni}_{2} \mathrm{Fe}_{3} / \mathrm{ZSM}-5$ facilitated the sugar to ketone reaction when compared to pure ZSM-5. The gas component was not analyzed in this work, however, it was believed the heterogeneous reactions might enhance the gas composition. In the future, analysis of the gas composition will be carried out.

In addition, future work on cluster catalysts is still needed to modify the ZSM-5 catalyst in order to test their property. On the other hand, more elements will be chosen to build new cluster catalysts to understand the catalytic activity in more detail.

Supplementary Materials: The following are available online at http://www.mdpi.com/2073-4344/10/2/178/s1, Figure S1: TG-DTA spectrum of (a) cellulose (b) cellulose with Ni2Fe3 catalyst. Table S1: Specific bio-oil compounds measured by GC-MS without catalyst. Table S2: Specific bio-oil compounds measured by GC-MS with Ni2Fe3 catalyst. Table S3: Specific bio-oil compounds measured by GC-MS with ZSM-5 catalyst. Table S4: Specific bio-oil compounds measured by GC-MS with Ni2Fe3/ZSM-5 catalyst. Table S5: Specific bio-oil compounds measured by GC-MS with ZSM-5 catalyst. Table S6: Specific bio-oil compounds measured by GC-MS with Ni2Fe3/ZSM-5 catalyst.

Author Contributions: Conceptualization, S.L.; experiment design, S.L. and J.S.C.; data analysis, S.L., S.C. and J.S.C.; writing—original draft preparation, S.L.; writing-review and editing, S.L., S.C. and J.S.C.; supervision, S.C. and J.S.C. All authors have read and agreed to the published version of the manuscript.

Funding: This work was financially supported by Professor Jeffrey Cross' laboratory budget at the Tokyo Institute of Technology.

Conflicts of Interest: The authors declare no conflict of interest.

\section{References}

1. Dudley, B. BP Statistical Review of World Energy, 68th ed.; B.P.: London, UK, 2019.

2. Liang, Q.M.; Fan, Y.; Wei, Y.M. The effect of energy end-use efficiency improvement on China's energy use and $\mathrm{CO}_{2}$ emissions: A CGE model-based analysis. Energy Effic. 2009, 2, 243-262. [CrossRef]

3. International Energy Outlook 2019 with Projections to 2050. Available online: https://www.eia.gov/ieo (accessed on 18 October 2019).

4. Some Snapshots of the Global Energy Situation. Available online: http://conversableeconomist.blogspot. com/2019/06/some-snapshots-of-global-energy.html (accessed on 13 June 2019).

5. Okkonen, L.; Lehtonen, O. Local, regional and national level of the socioeconomic impacts of a bio-oil production system-A case in Lieksa, Finland. Renew. Sustain. Energy Rev. 2017, 71, 103-111. [CrossRef]

6. Biotech Company Euglena Teams with ANA to Fuel Green Commercial Flights, Nikkei Asian Review. Available online: https://asia.nikkei.com/Business/Companies/Jet-biofuel-mass-production-to-begin-inJapan (accessed on 2 November 2018).

7. Lehto, J.; Oasmaa, A.; Solantausta, Y.; Kytö, M.; Chiaramonti, D. Review of fuel oil quality and combustion of fast pyrolysis bio-oils from lignocellulosic biomass. Appl. Energy 2014, 116, 178-190. [CrossRef]

8. Zhang, B.; Zhong, Z.; Ding, K.; Cao, Y.; Liu, Z. Catalytic Upgrading of Corn Stalk Fast Pyrolysis Vapors with Fresh and Hydrothermally Treated HZSM-5 Catalysts Using Py-GC/MS. Ind. Eng. Chem. Res. 2014, 53, 9979-9984. [CrossRef]

9. Iliopoulou, E.F.; Stefanidis, S.; Kalogiannis, K.; Psarras, A.C.; Delimitis, A.; Triantafyllidis, K.S.; Lappas, A.A. Pilot-scale validation of Co-ZSM-5 catalyst performance in the catalytic upgrading of biomass pyrolysis vapors. Green Chem. 2014, 16, 662-674. [CrossRef]

10. Yung, M.M.; Starace, A.K.; Mukarakate, C.; Crow, A.M.; Leshnov, M.A.; Magrini, K.A. Biomass Catalytic Pyrolysis on Ni/ZSM-5: Effects of Nickel Pretreatment and Loading. Energy Fuels 2016, 30, 5259-5268. [CrossRef]

11. Liu, W.J.; Li, W.W.; Jiang, H.; Yu, H.Q. Fates of Chemical Elements in Biomass during its Pyrolysis. Chem. Rev. 2017, 117, 6367-6398. [CrossRef]

12. Zhang, H.; Xiao, R.; Huang, H.; Xiao, G. Comparison of non-catalytic and catalytic fast pyrolysis of corncob in a fluidized bed reactor. Bioresour. Technol. 2009, 100, 1428-1434. [CrossRef] 
13. Uzun, B.B.; Sarioglu, N. Rapid and catalytic pyrolysis of corn stalks. Fuel Process. Technol. 2009, 90, 705-716. [CrossRef]

14. Muneer, B.; Zeeshan, M.; Qaisar, S.; Razzaq, M.; Lftikhar, H. Influence of in-situ and ex-situ HZSM-5 catalyst on co-pyrolysis of corn stalk and polystyrene with a focus on liquid yield and quality. J. Clean. Prod. 2019, 237, 117762. [CrossRef]

15. Chen, G.Y.; Li, J.; Liu, C.; Yan, B.B.; Cheng, Z.J.; Ma, W.C.; Yao, J.G.; Zhang, H. Low-temperature catalytic cracking of biomass gasification tar over Ni/HZSM-5. Waste Biomass Valorization 2019, 10, 1013-1020. [CrossRef]

16. Liu, J.C.; Ma, X.L.; Li, Y.; Wang, Y.G.; Xiao, H.; Li, J. Heterogeneous $\mathrm{Fe}_{3}$ single-cluster catalyst for ammonia synthesis via an associative mechanism. Nat. Commun. 2018, 9, 1610. [CrossRef] [PubMed]

17. Gong, L.; Chen, J.J.; $\mathrm{Mu}$, Y. Catalytic $\mathrm{CO}_{2}$ reduction to valuable chemicals using NiFe-based nanoclusters: A first-principles theoretical evaluation. Phys. Chem. Chem. Phys. 2017, 19, 28344-28353. [CrossRef] [PubMed]

18. Li, S.Y.; Cross, J.S. Reusability of the $\mathrm{Ni}_{2} \mathrm{Fe}_{3}$ metal catalyst for upgrading pyrolyzed bio-oil. In Proceedings of the MATEC Web of Conferences, Sapporo, Japan, 23-27 September 2019.

19. Nie, L.; de Souza, P.M.; Noronha, F.B.; An, W.; Sooknoi, T.; Resasco, D.E. Selective conversion of m-cresol to toluene over bimetallic Ni-Fe catalysts. J. Mol. Catal. A Chem. 2014, 47-55, 388-389. [CrossRef]

20. Yao, D.; Wu, C.; Yang, H.; Hu, Q.; Nahil, M.A.; Chen, H.; Williams, P.T. Hydrogen production from catalytic reforming of the aqueous fraction of pyrolysis bio-oil with modified Ni-Al catalysts. Int. J. Hydrogen Energy 2014, 39, 14642-14652. [CrossRef]

21. Behrens, M.; Cross, J.S.; Akasaka, H.; Ohtake, N. A study of guaiacol, cellulose, and Hinoki wood pyrolysis with silica, $\mathrm{ZrO}_{2} \& \mathrm{TiO}_{2}$ and ZSM-5 catalysts. J. Anal. Appl. Pyrolysis 2017, 125, 178-184.

22. Stefanidis, S.D.; Kalogiannis, K.G.; Iliopoulou, E.F.; Michailof, C.M.; Pilavachi, P.A.; Lappas, A.A. A study of lignocellulosic biomass pyrolysis via the pyrolysis of cellulose, hemicellulose and lignin. J. Anal. Appl. Pyrolysis 2014, 105, 143-150. [CrossRef]

23. Engineering ToolBox. Specific Heat of Some Metals. 2003. Available online: https://www.engineeringtoolbox. com/specific-heat-metals-d_152.html (accessed on 26 January 2020).

24. Madelung, O.; White, G.K. Thermal Conductivity of Pure Metals and Alloys; Springer: Berlin, Germany, 1991.

25. Xia, H.A.; Yan, X.P.; Xu, S.Q.; Yang, L.; Ge, Y.J.; Wang, J.; Zuo, S.L. Effect of Zn/ZSM-5 and FePO ${ }_{4}$ Catalysts $^{2}$ on Cellulose Pyrolysis. J. Chem. 2015, 2015, 749875. [CrossRef]

26. Fabbri, D.; Torri, C.; Baravelli, V. Effect of zeolites and nanopowder metal oxides on the distribution of chiral anhydrosugars evolved from pyrolysis of cellulose: An analytical study. J. Anal. Appl. Pyrolysis 2007, 80, 24-29. [CrossRef]

27. Lu, Q.; Wang, Z.; Dong, C.Q.; Zhang, Z.F.; Zhang, Y.; Yang, Y.P.; Zhu, X.F. Selective fast pyrolysis of biomass impregnated with $\mathrm{ZnCl}_{2}$ : Furfural production together with acetic acid and activated carbon as by-products. J. Anal. Appl. Pyrolysis 2011, 91, 273-279. [CrossRef]

28. Li, S.Y.; Yu, D.; Cheng, S.; Cross, J.S. Recycle Metal (Ni, Fe) Cluster Catalyst for Cellulose Pyrolysis to Upgrade Bio-oil. Biomass Bioenergy 2020. under review.

29. Iliopoulou, E.F.; Stefanidis, S.D.; Kalogiannis, K.G.; Delimitis, A.; Lappas, A.A.; Triantafyllidis, K.S. Catalytic upgrading of biomass pyrolysis vapors using transition metal-modified ZSM-5 zeolite. Appl. Catal. B Environ. 2012, 127, 281-290. [CrossRef]

30. Cheng, S.; Wei, L.; Julson, J.; Muthukumarappan, K.; Kharel, P.R. Upgrading pyrolysis bio-oil to hydrocarbon enriched biofuel over bifunctional Fe-Ni/HZSM-5 catalyst in supercritical methanol. Fuel Process. Technol. 2017, 167, 117-126. [CrossRef]

31. De, G.; Tapfer, L.; Catalano, M.; Battaglin, G.; Caccavale, F.; Gonella, F.; Mazzoldi, P.; Haglund, R.F., Jr. Formation of copper and silver nanometer dimension clusters in silica by the sol-gel process. Appl. Phys. Lett. 1996, 68, 3820-3822. [CrossRef]

32. Jayaprakash, J.; Srinivasan, N.; Chandrasekaran, P.; Girija, E.K. Synthesis and characterization of cluster of grapes like pure and Zinc-doped CuO nanoparticles by sol-gel method. Spectrochim. Acta Part A 2015, 136, 1803-1806. [CrossRef] [PubMed] 
33. Di Serio, M.; Ledda, M.; Cozzolino, M.; Minutillo, G.; Tesser, R.; Santacesaria, E. Transesterification of soybean oil to biodiesel by using heterogeneous basic catalysts. Ind. Eng. Chem. Res. 2006, 45, 3009-3014. [CrossRef]

34. Delfort, B.; le Pennec, D.; Lendresse, C. Process for Transesterification of Vegetable Oils or Animal Oils by Means of Heterogeneous Catalysts Based on Zinc or Bismuth, Titanium and Aluminum. U.S. Patent 7,151,187 B2, 19 December 2006.

(ㄷ) (1)

(C) 2020 by the authors. Licensee MDPI, Basel, Switzerland. This article is an open access article distributed under the terms and conditions of the Creative Commons Attribution (CC BY) license (http://creativecommons.org/licenses/by/4.0/). 